Pacific Journal of Mathematic 


\section{A THREE-TERM RELATION FOR SOME SUMS RELATED TO DEDEKIND SUMS}

\section{CARLITZ}

The object of the paper is to evaluate

$$
\begin{aligned}
& \sum_{r=0}^{a-1}\left[\frac{b(r+x)}{a}-y\right]\left[\frac{c(r+x)}{a}-z\right] \\
& +\sum_{s=0}^{b-1}\left[\frac{c(s+y)}{b}-z\right]\left[\frac{a(s+y)}{b}-x\right] \\
& +\sum_{t=0}^{c-1}\left[\frac{a(t+z)}{c}-x\right]\left[\frac{b(t+z)}{c}-y\right] .
\end{aligned}
$$

where $[u]$ is the greatest integer function,

$$
(b, c)=(c, a)=(a, b)=1 \text {. }
$$

and

$$
0 \leqq x<1, \quad 0 \leqq y<1, \quad 0 \leqq z<1
$$

1. Introduction. Put

$$
((x))=\left\{\begin{array}{cc}
x-[x]-\frac{1}{2} & (x \neq \text { integer }) \\
0 & (x=\text { integer }) .
\end{array}\right.
$$

The Dedekind sum $s(h, k)$ is defined by

$$
s(h, k)=\sum_{r(\bmod k)}\left(\left(\frac{r}{k}\right)\right)\left(\left(\frac{h r}{h}\right)\right) .
$$

It is well known that $s(h, k)$ satisfies the reciprocity relation [5]

$$
s(h, k)+s(k, h)=-\frac{1}{4}+\frac{1}{12}\left(\frac{h}{k}+\frac{1}{h k}+\frac{k}{h}\right),
$$

for $(h, k)=1$.

Rademacher [5] has proved the three-term relation

$$
s\left(b c^{\prime}, a\right)+s\left(c a^{\prime}, b\right)=s\left(a b^{\prime}, c\right)=-\frac{1}{4}+\frac{1}{12}\left(\frac{a}{b c}+\frac{b}{c a}+\frac{c}{a b}\right)
$$

where

$$
(b, c)=(c, a)=(a, b)=1
$$

and

$$
a a^{\prime} \equiv 1(\bmod b c), \quad b b^{\prime} \equiv 1(\bmod c a), \quad c c^{\prime} \equiv 1(\bmod a b)
$$


Rademacher [4] has introduced the sum

$$
s(h, k \mid x, y)=\sum_{r(\bmod k)}\left(\left(h \frac{r+y}{k}+x\right)\right)\left(\left(\frac{r+y}{k}\right)\right)
$$

and proved the reciprocity formula

$$
\begin{aligned}
& s(h, k \mid x, y)+s(k, h \mid y, x) \\
& \quad=((x))((y))+\frac{1}{2}\left\{\frac{h}{k} \bar{B}_{2}(y)+\frac{1}{h k} \bar{B}_{2}(h y+k x)+\frac{k}{h} \bar{B}_{2}(x)\right\},
\end{aligned}
$$

where $(h, k)=1, x$ and $y$ are not both integers and $\bar{B}_{2}(x)=B_{2}(x-[x])$, where $B_{2}(x)=x^{2}-x+1 / 6$, the Bernoulli polynomial of degree 2 .

In order to get a three-term relation for the generalized sum $s(h, k \mid x, y)$, the writer [2] defined

$$
s(a, b, c ; x, y, z)=\sum_{r(\bmod c)} \Phi\left(a \frac{t+z}{c}-x\right) \Phi\left(y-b \frac{t+z}{c}\right),
$$

where

$$
\Phi(x)=x-[x]-\frac{1}{2}
$$

and proved that

$$
\begin{aligned}
& s(a, b, c ; x, y, z)+s(b, c, a ; y, z, x)+s(c, a, b ; z, x, y) \\
& \quad=\delta-\frac{a}{2 b c} \bar{B}_{2}(c y-b z)-\frac{b}{2 c a} \bar{B}_{2}(a z-c x)-\frac{c}{2 a b} \bar{B}_{2}(b x-a y),
\end{aligned}
$$

where $(b, c)=(c, a)=(a, b)=1$ and $\delta=1$ if integers $r, s, t$ exist such that

$$
\frac{r+x}{a}=\frac{s+y}{b}=\frac{t+z}{c} ; 0 \leqq r<a, \quad 0 \leqq s<b, \quad 0 \leqq t<c ;
$$

$\delta=0$ otherwise. For $c=1, z=0$, it is easily verified that (1.10) reduces to (1.8).

The reciprocity Theorem (1.3) is equivalent to $[5, \mathrm{p} .9]$

$$
h \sum_{r=1}^{k-1} r\left[\frac{h r}{k}\right]+k \sum_{s=1}^{h-1} s\left[\frac{k s}{h}\right]=\frac{1}{12}(h-1)(k-1)(8 h k-h-k-1),
$$

where $(h, k)=1$. It is shown in [1] that (1.4) implies

$$
A(b, c ; a)+A(c, a ; b)+A(a, b ; c)=(a-1)(b-1)(c-1),
$$

where $(b, c)=(c, a)=(a, b)=1$ and

$$
A(b, c ; a)=\sum_{r=1}^{a-1}\left[\frac{b r}{a}\right]\left[\frac{c r}{a}\right] .
$$


It is not difficult to give a direct proof of (1.12) and indeed considerably more. It is also proved in [1] that

$$
\begin{aligned}
6 k & \sum_{r=0}^{k-1}\left[\frac{h r+z}{k}\right]^{2}+6 h \sum_{s=0}^{h-1}\left[\frac{k s+z}{h}\right]^{2} \\
& =(h-1)(2 h-1)(k-1)(2 k-1)+6[z]([z]+2 h k-h-k+1),
\end{aligned}
$$

where $(h, k)=1$ and $0 \leqq z<h+k$.

Generalizing (1.13), we define

$$
A(b, c ; a \mid y, z ; x)=\sum_{r=0}^{a-1}\left[\frac{b(r+x)}{a}-y\right]\left[\frac{c(r+x)}{a}-z\right]^{2} .
$$

In Theorem 2 below we evaluate

$$
R \equiv A(a, b ; c \mid x, y ; z)+A(b, c ; a \mid y, z ; x)+A(c, a ; b \mid z, x ; y),
$$

where $(b, c)=(c, a)=(a, b)=1$ and

$$
0 \leqq x<1, \quad 0 \leqq y<1, \quad 0 \leqq z<1 .
$$

It is however convenient to first consider the sum

$$
B(b, c ; a \mid y, z ; x)=\sum_{r=0}^{a-1}\left[y-\frac{b(r+x)}{a}\right]\left[z-\frac{c(r+x)}{a}\right],
$$

In Theorem 1 below we evaluate

$$
S \equiv B(a, b ; c \mid x, y ; z)+B(b, c ; a \mid y, z ; x)+A(c, a ; b \mid z, x ; y),
$$

where the parameters satisfy the same conditions as above.

The results are particularly simple if no two of the fractions

$$
\frac{r+x}{a}, \frac{s+y}{b}, \frac{t+z}{c} \quad(0 \leqq r<a, 0 \leqq s<b, 0 \leqq s<c)
$$

are equal. In this case we show that

$$
S=a b c, \quad R=(a-1)(b-1)(c-1)+1 .
$$

Also, if $x=y=z$, we have

$$
S=a b c-1, \quad R=(a-1)(b-1)(c-1) .
$$

The last form evidently includes (1.12).

It should be noted that (1.14) is not contained in the results of the present paper.

\section{Preliminaries.}

LEMma 1. For $a \geqq 1$, 


$$
[a x]=\sum_{r=0}^{a-1}\left[x+\frac{r}{a}\right]
$$

LEMMA 2. For $x \neq$ integer,

$$
[-x]=-[x]-1
$$

LEMMA 3. Put $\Phi(x)=x-[x]-1 / 2$. Then $\Phi(x+1)=\Phi(x)$ and

$$
\Phi(a x)=\sum_{r(\bmod a)} \Phi\left(x+\frac{r}{a}\right)
$$

LEMMA 4. For $a \geqq 1,(b, a)=1$,

$$
\sum_{r=0}^{a-1}\left[x+\frac{b r}{a}\right]=[a x]+\frac{1}{2}(a-1)(b-1) \text {. }
$$

Lemmas 1, 2, 3 are well-known. To prove Lemma 4, take

$$
\begin{aligned}
\sum_{r=0}^{a-1}\left[x+\frac{b r}{a}\right] & =\sum_{r=0}^{a-1}\left\{x+\frac{b r}{a}-\Phi\left(x+\frac{b r}{a}\right)-\frac{1}{2}\right\} \\
& =a x+\frac{1}{2} b(a-1)-\Phi(a x)-\frac{1}{2} a \\
& =[a x]+\frac{1}{2} a b-\frac{1}{2} a-\frac{1}{2} b+\frac{1}{2} \\
& =[a x]+\frac{1}{2}(a-1)(b-1) .
\end{aligned}
$$

3. Three term relation for $B(a, b ; c \mid x, y ; z)$. We assume in the remainder of the paper that

$$
(b, c)=(c, a)=(a, b)=1
$$

and

$$
0 \leqq x<1, \quad 0 \leqq y<1, \quad 0 \leqq z<1
$$

Also we write

$$
\sum_{r, s, t} \equiv \sum_{r=0}^{a-1} \sum_{s=0}^{b-1} \sum_{t=0}^{c-1}
$$

It is convenient to define

$$
B(a, b ; c \mid x, y ; z)=\sum_{t=0}^{c-1}\left[x-\frac{a(t+z)}{c}\right]\left[y-\frac{b(t+z)}{c}\right] .
$$

By Lemma 1, this gives 
(3.4)

$$
B(a, b ; c \mid x, y, z)=\sum_{r, s, t}\left[\frac{r+x}{a}-\frac{t+z}{c}\right]\left[\frac{s+y}{b}-\frac{t+z}{c}\right] .
$$

Put

$$
\xi=\frac{r+x}{a}, \quad \eta=\frac{s+y}{b}, \quad \zeta=\frac{t+z}{c}
$$

Thus (3.4) becomes

$$
B(a, b ; c \mid x, y ; z)=\sum_{r, s, t}[\xi-\zeta][\eta-\zeta] .
$$

To begin with, we assume that no two of the fractions

$$
\frac{r+x}{a}, \frac{s+y}{b}, \frac{t+z}{c} \quad(0 \leqq r<a, 0 \leqq s<b, 0 \leqq t<c)
$$

differ by an integer. It is easily seen that this is equivalent to requiring that no two of the fractions are equal. We shall refer to this as Case 1. Case 2 is that in which exactly two of the fractions are equal, Case 3 that in which all three are equal. If a pair $r, s$ exists such that

$$
\frac{r+x}{a}=\frac{s+y}{b}
$$

it is easily shown to be unique.

Thus in Case 1 we have, by Lemma 2,

$$
[\xi-\zeta]=-[\zeta-\xi]-1,
$$

so that (3.5) becomes

$$
B(a, b ; c \mid x, y ; z)=-\sum_{r, s, t}[\eta-\zeta][\zeta-\xi]-\sum_{r, s, t}[\eta-\zeta] \cdot
$$

Hence

$$
\begin{aligned}
& B(a, b ; c \mid x, y ; z)+B(b, c ; a \mid y, z ; x)+B(c, a ; b \mid z, x ; y) \\
&=-\sum_{r, s, t}\{[\eta-\zeta][\zeta-\xi]+[\zeta-\xi][\xi-\eta]+[\xi-\eta][\eta-\zeta] \\
&+[\eta-\zeta]+[\zeta-\xi]+[\xi-\eta]\} \\
&=-\sum_{r, s, t}\left\{[\eta-\zeta]+\frac{1}{2}\right)\left([\zeta-\xi]+\frac{1}{2}\right) \\
&+\left([\zeta-\xi]+\frac{1}{2}\right)\left([\xi-\eta]+\frac{1}{2}\right) \\
&\left.+\left([\xi-\eta]+\frac{1}{2}\right)\left([\eta-\zeta]+\frac{1}{2}\right)\right\}+\frac{3}{4} a b c .
\end{aligned}
$$

Hence if we put 


$$
T=\sum_{r, s, t}\left\{[\eta-\zeta]+[\zeta-\xi]+[\xi-\eta]+\frac{3}{2}\right\}^{2},
$$

it is clear that

$$
\begin{aligned}
T= & \sum_{r, s, t}\left\{\left([\eta-\zeta]+\frac{1}{2}\right)^{2}+\left([\zeta-\xi]+\frac{1}{2}\right)^{2}\right. \\
& \left.+\left([\xi-\eta]+\frac{1}{2}\right)^{2}\right\}+\frac{3}{2} a b c-2 S,
\end{aligned}
$$

where

(3.11) $S=B(a, b ; c \mid x, y ; z)+B(b, c ; a \mid y, z ; x)+B(c, a ; b \mid z, x ; y)$.

Since

$$
[\eta-\zeta]+[\zeta-\xi]+[\xi-\eta]=-1 \text { or }-2(\text { Case } 1 \text { or } 2),
$$

it follows that

$$
\left.T=\frac{1}{4} a b c \quad \text { (Case } 1 \text { or } 2\right) \text {. }
$$

Also since each of $[\eta-\zeta],[\zeta-\xi],[\xi-\eta]=0$ or -1 , we get

$$
\sum_{r, s, t}\left\{\left([\eta-\zeta]+\frac{1}{2}\right)^{2}+\left([\zeta-\xi]+\frac{1}{2}\right)^{2}+\left([\xi-\eta]+\frac{1}{2}\right)^{2}\right\}=\frac{3}{4} a b c .
$$

Thus (3.11) reduces to simply

$$
S=a b c \quad(\text { Case } 1) .
$$

Turning next to Case 2, let $r_{0}, s_{0}$ satisfy

$$
\xi_{0}=\frac{r_{0}+x}{a}=\frac{s_{0}+y}{b}=\eta_{0} \text {. }
$$

For this pair we have

$$
\left[\eta_{0}-\xi_{0}\right]=-\left[\xi_{0}-\eta_{0}\right]=0
$$

rather than (3.7). Thus

$$
\begin{aligned}
B(b, c ; a \mid y, z ; x)= & -\sum_{r, s, t}([\zeta-\xi][\xi-\eta] \\
& +[\zeta-\xi])+\sum_{t}\left[\zeta-\xi_{0}\right] .
\end{aligned}
$$

Since

$$
\sum_{t}\left[\zeta-\xi_{0}\right]=\sum_{t=0}^{c-1}\left[\frac{t+z}{c}-\xi_{0}\right]=\left[z-c \xi_{0}\right],
$$

we get, in place of (3.13), 


$$
S=a b c+\left[z-c \xi_{0}\right] \quad(\text { Case 2) . }
$$

For Case 3 , let $r_{0}, s_{0}, t_{0}$ satisfy $\xi_{0}=\eta_{0}=\zeta_{0}$, that is

$$
\frac{r_{0}+x}{a}=\frac{s_{0}+y}{b}=\frac{t_{0}+z}{c} \text {. }
$$

Equation (3.14) remains unchanged. Since

$$
T=\frac{1}{4} a b c+2 \quad(\text { Case } 3),
$$

we therefore get

$$
S=a b c-1+\left[x-a \zeta_{0}\right]+\left[y-b \xi_{0}\right]+\left[z-c \eta_{0}\right] \quad(\text { Case } 3) .
$$

Since

$$
\left[x-a \zeta_{0}\right]=\left[x-a \xi_{0}\right]=\left[x-\left(r_{0}+x\right)\right]=-r_{0}, \text { etc. , }
$$

we may replace (3.16) by

$$
S=a b c-1-r_{0}-s_{0}-t_{0} \quad(\text { Case } 3) .
$$

We may now state

THEOREM 1. Let $(b, c)=(c, a)=(a, b)=1$ and

$$
0 \leqq x<1, \quad 0 \leqq y<1, \quad 0 \leqq z<1 .
$$

Then

$$
\mathrm{S}=B(a, b ; c \mid x, y ; z)+B(b, c ; a \mid y, z ; x)+B(c, a ; b \mid z, x ; y)
$$

is evaluated by (3.13), (3.15) and (3.16).

In particular, for $x=y=z$, we have

COROLLARY 1.

$$
\begin{aligned}
\sum_{r=0}^{a-1} & {\left[x-\frac{b(r+x)}{a}\right]\left[x-\frac{c(r+x)}{a}\right] } \\
& +\sum_{s=0}^{b-1}\left[x-\frac{c(s+x)}{b}\right]\left[x-\frac{b(s+x)}{b}\right] \\
& +\sum_{t=0}^{c-1}\left[x-\frac{a(t+x)}{c}\right]\left[x-\frac{b(t+x)}{c}\right]=a b c-1 .
\end{aligned}
$$

4. Three-term relations for $A(a, b ; c \mid x, y ; z)$. We again first consider Case 1. Thus in 


$$
A(a, b ; c \mid x, y ; z)=\sum_{t=0}^{c-1}\left[\frac{a(t+z)}{c}-x\right]\left[\frac{b(t+z)}{c}-y\right],
$$

none of the quantities

$$
\frac{a(t+z)}{c}-x, \quad \frac{b(t+z)}{c}-y \quad(0 \leqq t<c)
$$

is an integer. It follows that

$$
\begin{aligned}
A(a, b ; c \mid x, y ; z)= & \sum_{t=0}^{c-1}\left\{1+\left[x-\frac{a(t+z)}{c}\right]\right\}\left\{1+\left[y-\frac{b(t+z)}{c}\right]\right\} \\
= & c+\sum_{t=0}^{c-1}\left[x-\frac{a(t+z)}{c}\right]+\sum_{t=0}^{c-1}\left[y-\frac{b(t+z)}{c}\right] \\
& +B(a, b ; c \mid x, y ; z) .
\end{aligned}
$$

Thus by Lemma 4 , we get

$$
\begin{aligned}
& A(a, b ; c \mid x, y ; z) \\
& \quad=[c x-a z]+[c y-b z]-\frac{1}{2} a c-\frac{1}{2} b c+\frac{1}{2} a+\frac{1}{2} b+1 \\
& \quad+B(a, b ; c \mid x, y ; z) .
\end{aligned}
$$

Let

$$
R=A(a, b ; c \mid x, y ; z)+A(b, c ; a \mid y, z ; x)+A(c, a ; b \mid z, x ; y) .
$$

Then by (4.1) and (3.13) we get

$$
\begin{aligned}
R= & {[c x-a z]+[c y-b z]+[a y-b x]+[a z-c x] } \\
& +[b z-c y]+[b x-a y]-(b c+c a+a b) \\
& +(a+b+c)+3+S .
\end{aligned}
$$

Applying Lemma 2, this reduces to

$$
R=(a-1)(b-1)(c-1)+1 \quad \text { (Case } 1) .
$$

As for Case 2, let $r_{0}, s_{0}$ denote the exceptional pair, that is,

$$
\begin{aligned}
\xi_{0}= & \frac{r_{0}+x}{a}=\frac{s_{0}+y}{b}=\eta_{0} . \\
A(b, c ; a \mid y, z ; x)= & \sum_{r=0}^{a-1}\left[\frac{b(r+x)}{a}-y\right]\left[\frac{c(r+x)}{a}-z\right] \\
= & \sum_{r=0}^{a-1}\left\{1+\left[y-\frac{b(r+x)}{a}\right]\right\}\left\{1+\left[z-\frac{c(r+x)}{a}\right]\right\} \\
& -\left\{1+\left[z-\frac{c\left(r_{0}+x\right)}{a}\right]\right\} .
\end{aligned}
$$


Then, as above, it follows that

$$
\begin{aligned}
A(b, c ; a \mid y, z ; x)= & B(b, c ; a \mid y, z ; x)+[a y-b x]+[a z-c x] \\
& +\frac{1}{2} b+\frac{1}{2} c-\frac{1}{2} a b-\frac{1}{2} a c-\left[z-c \xi_{0}\right] .
\end{aligned}
$$

Similarly

$$
\begin{aligned}
A(c, a ; b \mid z, x ; y)= & B(c, a ; b \mid z, x ; y)+[b x-a y]+[b z-c y] \\
& +\frac{1}{2} a+\frac{1}{2} c-\frac{1}{2} a b-\frac{1}{2} b c-\left[z-c \eta_{0}\right] .
\end{aligned}
$$

However (4.1) remains unchanged.

Thus

$$
R=S-(b c+c a+a b)+(a+b+c)-1-2\left[z-c \eta_{0}\right] .
$$

Therefore, by (3.15), we have

$$
R=(a-1)(b-1)(c-1)-\left[z-c \eta_{0}\right] \quad(\text { Case 2) . }
$$

Finally, for Case 3 , let $r_{0}, s_{0}, t_{0}$, be the exceptional triple:

$$
\frac{r_{0}+x}{a}=\frac{s_{0}+y}{b}=\frac{t_{0}+z}{c} \quad\left(\xi_{0}=\eta_{0}=\zeta_{0}\right) .
$$

We now have

$$
\begin{aligned}
A(b, c ; a \mid y, z ; x)= & \sum_{r=0}^{a-1}\left\{1+\left[y-\frac{b(r+x)}{a}\right]\right\}\left\{1+\left[z-\frac{c(r+x)}{a}\right]\right\} \\
& -1-\left[y-b \xi_{0}\right]-\left[z-b \xi_{0}\right] .
\end{aligned}
$$

Thus in place of (4.6) we get

$$
\begin{aligned}
& A(b, c ; a \mid y, z ; x) \\
& \quad=B(b, c ; a \mid y, z ; x)+[a y-b x]+[a z-c x] \\
& \quad+\frac{1}{2} b+\frac{1}{2} c-\frac{1}{2} a b-\frac{1}{2} a c-\left[y-b \xi_{0}\right]-\left[z-c \xi_{0}\right] .
\end{aligned}
$$

There are similar formulas for $A(c, a ; b \mid z, x ; y)$ and $A(a, b ; c \mid x, y ; z)$. Since

$$
\begin{aligned}
{[c y-b z]+[b z-c x] } & =[a z-c x]+[c x-a z] \\
& =[b x-a y]+[a y-b x]=0,
\end{aligned}
$$

it follows that 


$$
\begin{aligned}
R= & S+a+b+c-b c-c a-a b-\left[y-b \xi_{0}\right]-\left[z-c \xi_{0}\right] \\
& -\left[z-c \eta_{0}\right]-\left[x-a \eta_{0}\right]-\left[x-a \zeta_{0}\right]-\left[y-b \zeta_{0}\right] \\
= & S+a+b+c-b c-c a-a b \\
& -2\left[x-a \xi_{0}\right]-2\left[y-b \eta_{0}\right]-2\left[z-c \zeta_{0}\right] .
\end{aligned}
$$

Making use of (3.16) we get

$$
\text { (4.11) } R=(a-1)(b-1)(c-1)-\left[x-a \xi_{0}\right]-\left[y-b \eta_{0}\right]-\left[z-c \zeta_{0}\right]
$$

or, if we prefer,

$$
R=(a-1)(b-1)(c-1)+r_{0}+s_{0}+t_{0} \quad(\text { Case } 3) .
$$

This completes the proof of

THEOREM 2. Let $(b, c)=(c, a)=(a, b)=1$ and

$$
0 \leqq x<1, \quad 0 \leqq y<1, \quad 0 \leqq x<1 \text {. }
$$

Then

$$
R=A(a, b ; c \mid x, y ; z)+A(b, c ; a \mid y, z ; x)+A(c, a ; b \mid z, x ; y)
$$

is evaluated by (4.4), (4.8) and (4.11).

In particular, for $x=y=z$, we have

\section{COROLlary 2.}

$$
\begin{aligned}
& \sum_{r=0}^{a-1}\left[\frac{b(r+x)}{a}-x\right]\left[\frac{c(r+x)}{a}-x\right] \\
& \quad+\sum_{s=0}^{b-1}\left[\frac{c(s+x)}{b}-x\right]\left[\frac{a(s+x)}{b}-x\right] \\
& \quad+\sum_{t=1}^{c-1}\left[\frac{a(t+x)}{c}-x\right]\left[\frac{b(t+x)}{c}-x\right]=(a-1)(b-1)(c-1) .
\end{aligned}
$$

\section{REFERENCES}

1. L. Carlitz, Some sums containing the greatest integer function, Revue Roumaine de Mathématiques pures et appliquées, to appear.

2. — A three-term relation for the Dedekind-Rademacher sums, Publications Mathematicae, 14 (1967), 119-124.

3. H. Rademacher, Generalization of the reciprocity theorem for Dedekind sums, Duke Math. J., 21 (1954), 391-398.

4. - Some remarks on certain generalized Dedekind sums, Acta Arithmetica, 9 (1964), 97-105.

5. H. Rademacher and E. Grosswald, Dedekind Sums, The Mathematical Association of America, 1972.

Received October 31, 1974. Supported in part by NSF grant GP-37924XI. 


\section{PACIFIC JOURNAL OF MATHEMATICS}

\section{EDITORS}

RICHARD ARENS (Managing Editor)

University of California

Los Angeles, California 90024

\section{J. DugundJI}

Department of Mathematics University of Southern California Los Angeles, California 90007

D. Gilbarg and J. Milgram

Stanford University

Stanford, California 94305
University of Washington Seattle, Washington 98105

\section{ASSOCIATE EDITORS}
E. F. BECKENBACH
B. H. NeumanN
F. WolF
K. YoShIDA

\section{SUPPORTING INSTITUTIONS}

\author{
UNIVERSITY OF SOUTHERN CALIFORNIA \\ STANFORD UNIVERSITY \\ UNIVERSITY OF TOKYO \\ UNIVERSITY OF UTAH \\ WASHINGTON STATE UNIVERSITY \\ UNIVERSITY OF WASHINGTON \\ $\stackrel{*}{*} \stackrel{*}{*} \stackrel{*}{ }{ }^{*}$ AMERICAN MATHEMATICAL SOCIETY
}

The Supporting Institutions listed above contribute to the cost of publication of this Journal, but they are not owners or publishers and have no responsibility for its content or policies.

Mathematical papers intended for publication in the Pacific Journal of Mathematics should be in typed form or offset-reproduced, (not dittoed), double spaced with large margins. Underline Greek letters in red, German in green, and script in blue. The first paragraph or two must be capable of being used separately as a synopsis of the entire paper. Items of the bibliography should not be cited there unless absolutely necessary, in which case they must be identified by author and Journal, rather than by item number. Manuscripts, in triplicate, may be sent to any one of the editors. Please classify according to the scheme of Math. Reviews, Index to Vol. 39. All other communications should be addressed to the managing editor, or Elaine Barth, University of California, Los Angeles, California, 90024.

The Pacific Journal of Mathematics expects the author's institution to pay page charges, and reserves the right to delay publication for nonpayment of charges in case of financial emergency.

100 reprints are provided free for each article, only if page charges have been substantially paid. Additional copies may be obtained at cost in multiples of 50 .

The Pacific Journal of Mathematics is issued monthly as of January 1966. Regular subscription rate: $\$ 72.00$ a year (6 Vols., 12 issues). Special rate: $\$ 36.00$ a year to individual members of supporting institutions.

Subscriptions, orders for back numbers, and changes of address should be sent to Pacific Journal of Mathematics, 103 Highland Boulevard, Berkeley, California, 94708.

\section{PUBLISHED BY PACIFIC JOURNAL OF MATHEMATICS, A NON-PROFIT CORPORATION}

Printed at Kokusai Bunken Insatsusha (International Academic Printing Co., Ltd.), 270, 3-chome Totsuka-cho, Shinjuku-ku, Tokyo 160, Japan.

\section{Copyright (C) 1975 by Pacific Journal of Mathematics} Manufactured and first issued in Japan 


\section{Pacific Journal of Mathematics}

\section{Vol. 57, No. $2 \quad$ February, 1975}

Norman Larrabee Alling, On Cauchy's theorem for real algebraic curves with boundary .......

Daniel D. Anderson, A remark on the lattice of ideals of a Prüfer domain ..................

Dennis Neal Barr and Peter D. Miletta, A necessary and sufficient condition for uniqueness of

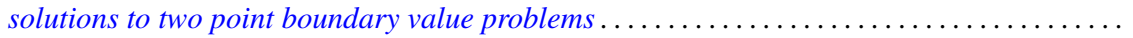

Ladislav Beran, On solvability of generalized orthomodular lattices . . . . . . . . . . ........

L. Carlitz, A three-term relation for some sums related to Dedekind sums . . . . . . . . . .....

Arthur Herbert Copeland, Jr. and Albert Oscar Shar, Images and pre-images of localization

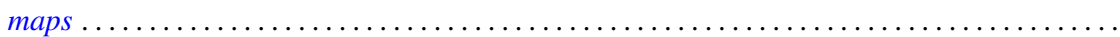

G. G. Dandapat, John L. Hunsucker and Carl Pomerance, Some new results on odd perfect

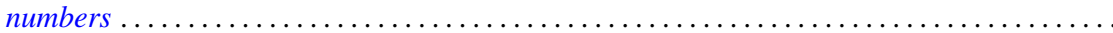

M. Edelstein and L. Keener, Characterizations of infinite-dimensional and nonreflexive

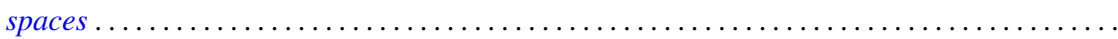

Francis James Flanigan, On Levi factors of derivation algebras and the radical embedding

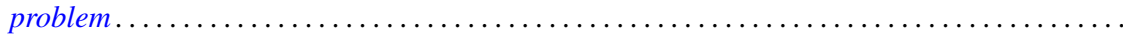

Harvey Friedman, Provable equality in primitive recursive arithmetic with and without

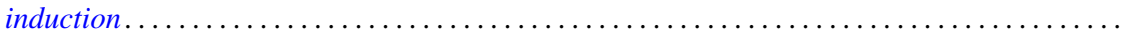

Joseph Braucher Fugate and Lee K. Mohler, The fixed point property for tree-like continua with

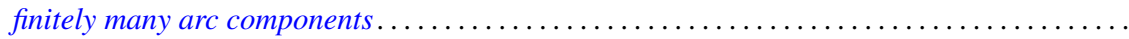

John Norman Ginsburg and Victor Harold Saks, Some applications of ultrafilters in

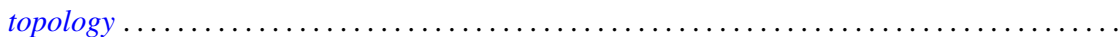

Arjun K. Gupta, Generalisation of a "square" functional equation .....................

Thomas Lee Hayden and Frank Jones Massey, Nonlinear holomorphic semigroups ..........

V. Kannan and Thekkedath Thrivikraman, Lattices of Hausdorff compactifications of a locally

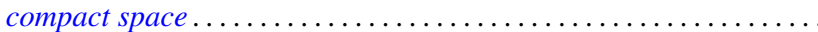

J. E. Kerlin and Wilfred Dennis Pepe, Norm decreasing homomorphisms between group

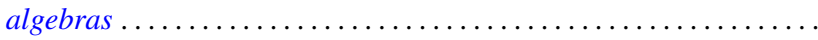

Young K. Kwon, Behavior of $\Phi$-bounded harmonic functions at the Wiener boundary ...

Richard Arthur Levaro, Projective quasi-coherent sheaves of modules .

Chung Lin, Rearranging Fourier transforms on groups...........................

David Lowell Lovelady, An asymptotic analysis of an odd order linear differential equation . . 4475

Jerry Malzan, On groups with a single involution .......................... 481

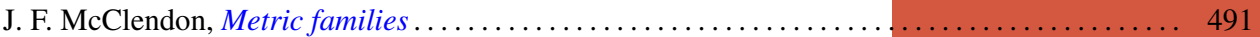

Carl Pomerance, On multiply perfect numbers with a special property .

Mohan S. Putcha and Adil Mohamed Yaqub, Polynomial constraints for finiteness of semisimple rings. .

Calvin R. Putnam, Hyponormal contractions and strong power convergence . . . . . . . . . 531

Douglas Conner Ravenel, Multiplicative operations in $\mathrm{BP} * \mathrm{BP} \ldots \ldots \ldots \ldots \ldots \ldots \ldots \ldots \ldots .539$

Judith Roitman, Attaining the spread at cardinals which are not strong limits . . . . . . . . . 545

Kazuyuki Saitô, Groups of *-automorphisms and invariant maps of von Neumann algebras . . . 553

Brian Kirkwood Schmidt, Homotopy invariance of contravariant functors acting on smooth

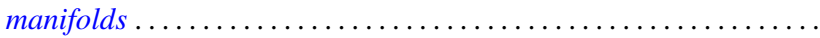

Kenneth Barry Stolarsky, The sum of the distances to $N$ points on a sphere.

Mark Lawrence Teply, Semiprime rings with the singular splitting property.

J. Pelham Thomas, Maximal connected Hausdorff spaces..............

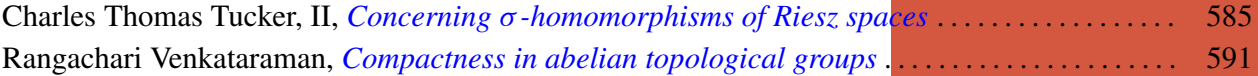

William Charles Waterhouse, Basically bounded functors and flat sheaves . . . . . . . . . . . 597

David Westreich, Bifurcation of operator equations with unbounded linearized part ......... 611

William Robin Zame, Extendibility, boundedness and sequential convergence in spaces of 